\title{
One or Two Low Affinity Penicillin-binding Proteins May Be Responsible for the Range of Susceptibility of Enterococcus faecium to Benzylpenicillin
}

\author{
By RUSSELL WILLIAMSON, ${ }^{1}$ * CHANTAL LE BOUGUÉNEC, ${ }^{2}$ \\ LAURENT GUTMANN ${ }^{1}$ AND THEA HORAUD ${ }^{2}$ \\ ${ }^{1}$ Laboratoire de Microbiologie Médicale, Université Pierre et Marie Curie, 15-21, \\ rue de l'Ecole de Médecine, 75270 Paris, Cedex 06, France \\ ${ }^{2}$ Reference Centre of Streptococci (Laboratoire des Staphylocoques et des Streptocoques), \\ Institut Pasteur, 75724 Paris, Cedex 15, France
}

(Received 11 December 1984 ; revised 18 March 1985)

Three benzylpenicillin-resistant, clinical isolates of Enterococcus faecium (MIC values 16$64 \mu \mathrm{g} \mathrm{ml}^{-1}$ ) contained six penicillin-binding proteins (PBPs), of which PBP5 was the most abundant and had the lowest affinity for the antibiotic. Four benzylpenicillin-susceptible strains (MIC values $0.031-0.5 \mu \mathrm{g} \mathrm{ml}^{-1}$ ) were obtained as spontaneous derivatives from these above organisms. There were significant decreases in the amounts of PBP5 in each of the derivatives, with the concomitant appearance of a new, higher affinity PBP $\left(5^{*}\right)$ in three strains. Increased amounts of PBP5, with no changes in PBP5*, were found in several mutants with intermediatelevel benzylpenicillin-resistance (MIC values 1-8 $\mathrm{g} \mathrm{m}^{-1}$ ) selected from two of the susceptible strains. Examination of 18 other clinical isolates, with a wide range of susceptibilities to benzylpenicillin (MIC values $0.062-128 \mu \mathrm{g} \mathrm{ml}^{-1}$ ), showed that PBP5* was present in 13 strains, and PBP5 in all of them, but in differing amounts. The results concerning the relative amounts and relative affinities of PBPs $5^{*}$ and 5 allowed the categorization of the various strains into six groups, within which organisms had somewhat similar susceptibilities to benzylpenicillin.

\section{INTRODUCTION}

Most $(70 \%)$ clinical isolates of Enterococcus faecium are currently multiply resistant to a variety of antibiotics including $\beta$-lactam antibiotics, tetracycline, erythromycin and other macrolides, aminoglycosides (high level) and chloramphenicol (Horodniceanu \& Delbos, 1980). The natural resistance level of E. faecium to benzylpenicillin is assumed to be entirely due to the interactions of the antibiotic with the penicillin-binding proteins (PBPs) (Coyette et al., 1980) since $\beta$-lactamase activity has not been detected (Le Bouguénec \& Horodniceanu, 1982; Weinstein \& Moellering, 1975) and the cell wall does not act as a permeability barrier (Williamson et al., 1983). In a study of two strains of $E$. faecium selected in vitro which had become extraordinarily susceptible to a variety of $\beta$-lactam antibiotics, Eliopoulos et al. (1982) showed that there were no apparent changes in the PBPs of these strains when compared with those of the wild-type, parental strains. Moreover, the susceptibilities of these strains to a variety of other antibiotics were generally the same as the parental strains.

Previous results (Le Bouguénec \& Horodniceanu, 1982) showed that resistance to tetracycline, erythromycin, aminoglycosides and chloramphenicol could be transferred by conjugation from $E$. faecium into $E$. faecalis, but that resistance to benzylpenicillin was not transferred. To extend these experiments, derivatives were obtained from three clinical isolates of $E$. faecium in which either single or multiple resistance characteristics were lost, either spontaneously or by treatment with ethidium bromide, in particular with a 32- to 2000-fold increase in susceptibility

Abbreviation: PBP, penicillin-binding protein. 
to benzylpenicillin. In the present studies we have examined the PBPs of these strains to determine the cause of the loss of this resistance. We also examined the PBPs in an additional 18 clinical isolates of $E$. faecium, which also had a 2000 -fold range in susceptibilities to benzylpenicillin, with a variety of additional resistance patterns, to determine if the results obtained with the derivatives selected in vitro were applicable to the natural isolates.

\section{METHODS}

Bacterial strains and growth conditions. The 21 strains of E. faecium, identified by the criteria of Facklam (1972), were from the collection of the Reference Centre of Streptococci, Institut Pasteur, Paris, France, and originally all were clinical isolates. Bacteria were grown without aeration at $37^{\circ} \mathrm{C}$ in Brain-Heart Infusion broth (BHI; Difco), and growth was monitored with a Perkin-Elmer Junior III spectrophotometer at $650 \mathrm{~nm}$.

Antibiotics and reagents. Benzylpenicillin and streptomycin were obtained from Specia, Paris, France, chloramphenicol and erythromycin from Roussel-Uclaf, Romainville, France, kanamycin from Bristol Laboratories, Paris, France, and tetracycline from Laboratoires Diamant, Puteaux, France. $\left[{ }^{3} \mathrm{H}\right]$ Benzylpenicillin ( $26 \mathrm{Ci} \mathrm{mmol}^{-1} ; 0.66 \mathrm{TBq} \mathrm{mmol}^{-1}$ ) was generously provided by Rhône-Poulenc Recherche, Vitry-sur-Seine, France, and synthesized at the Service des Molécules Marquées, Commissariat à l'Energie Atomique, Gif-surYvette, France. Lysozyme was purchased from Sigma, and M1-muramidase was the generous gift of K. Yokogawa, Dainippon Pharmaceutical Co., Suita/Osaka, Japan.

Susceptibility tests. Minimum inhibitory concentration (MIC) values were determined using twofold dilutions of antibiotics in BHI agar. Approximately $10^{4}$ colony-forming units were applied to the agar surface with a Steers replicator. Plates were incubated for $18 \mathrm{~h}$ at $37^{\circ} \mathrm{C}$.

Isolation of antibiotic-susceptible and benzylpenicillin-resistant strains. Antibiotic-susceptible strains were obtained either spontaneously or by treatment of resistant strains with ethidium bromide at $42{ }^{\circ} \mathrm{C}$ as previously described (Horodniceanu et al., 1976). Spontaneous, benzylpenicillin-resistant mutants were obtained by plating approximately $10^{9}$ exponential-phase organisms onto $\mathrm{BHI}$ agar containing benzylpenicillin at twofold increasing concentrations from the MIC up to $64 \times$ MIC. Colonies were picked from plates up to the highest concentration of antibiotic allowing growth after $48 \mathrm{~h}$ incubation at $37^{\circ} \mathrm{C}$, and streaked onto $\mathrm{BHI}$ agar containing appropriate amounts of benzylpenicillin.

Analysis of penicillin-binding proteins. The technique used was a modification of that used previously (Williamson et al., 1983). Exponential-phase organisms $\left(\mathrm{OD}_{650}\right.$ of $0 \cdot 25$, approximately $2 \times 10^{8}$ bacteria ml $\left.{ }^{-1}\right)$ were rapidly chilled in ice, centrifuged $\left(5000 \mathrm{~g}\right.$ for $2 \mathrm{~min}$ at $2{ }^{\circ} \mathrm{C}$ ), resuspended in ice-cold $50 \mathrm{~mm}$-sodium phosphate buffer, pH 7.0 $\left(0.04 \times\right.$ original volume), and samples $(40 \mu \mathrm{l})$ were incubated with various amounts of $\left[{ }^{3} \mathrm{H}\right]$ benzylpenicillin $(0.0002-20 \mu \mathrm{g})$ in a final volume of $50 \mu \mathrm{l}$ for $30 \mathrm{~min}$ at $37^{\circ} \mathrm{C}$. All PBPs were saturated within $15 \mathrm{~min}$ at the highest concentration of antibiotic. The samples were then placed in ice, an excess of unlabelled benzylpenicillin was added $\left(2 \mathrm{ml}\right.$ of $\left.1 \mathrm{mg} \mathrm{ml}^{-1}\right)$, and the bacteria were recovered by further centrifugation as above. The supernates were removed by aspiration, and organisms were resuspended in $20 \mu \mathrm{l}$ sodium phosphate buffer containing $10 \mu \mathrm{g}$ lysozyme, $10 \mu \mathrm{g}$ M1-muramidase and $0.1 \%$ (w/v) Triton X-100, and the samples were incubated at $37^{\circ} \mathrm{C}$ for 20 min to cause complete lysis.

The PBPs in the lysates were analysed by SDS-PAGE and fluorography as previously described (Williamson $e t$ al., 1983), except that the final concentrations of acrylamide and $N, N^{\prime}$-bis-acrylamide in the separating gels were reduced to $6 \%(\mathrm{w} / \mathrm{v})$ and $0.08 \%(\mathrm{w} / \mathrm{v})$, respectively, to enable a significantly better resolution of the individual PBPs. Band densities of the PBPs on the fluorograms were quantified with a Helena Laboratories Cliniscan (Beaumont, Texas, USA) and were corrected for any variations in width. The data presented are the means of at least two experiments with each strain, and the variation was generally less than $7 \%$ of the mean.

\section{RESULTS}

\section{Antibiotic susceptibilities and PBPs of parental and mutant strains}

The antibiotic susceptibilities of the three wild-type clinical isolates and a variety of derivatives obtained from them are presented in Table 1. Strains D359, D371 and D344 were resistant to benzylpenicillin (MIC values $16-64 \mu \mathrm{g} \mathrm{ml}^{-1}$ ), tetracycline (MIC values 64$256 \mu \mathrm{g} \mathrm{ml}^{-1}$ ), erythromycin (MIC values $>1024 \mu \mathrm{g} \mathrm{ml}^{-1}$ ) and to high levels of kanamycin (MIC values $>8000 \mu \mathrm{g} \mathrm{ml}^{-1}$ ) and streptomycin (MIC values $>2000 \mu \mathrm{g} \mathrm{ml}^{-1}$ ); strain D371 was also resistant to chloramphenicol (MIC $32 \mu \mathrm{g} \mathrm{ml}^{-1}$ ). Resistance to erythromycin, as well as to other macrolides and related antibiotics (MLS phenotype), was lost spontaneously from strain D359 to give BM6223. This strain and D344 were cured of aminoglycoside resistance by treatment with ethidium bromide to give strains BM6224 and BM6219, respectively. In contrast, strains 


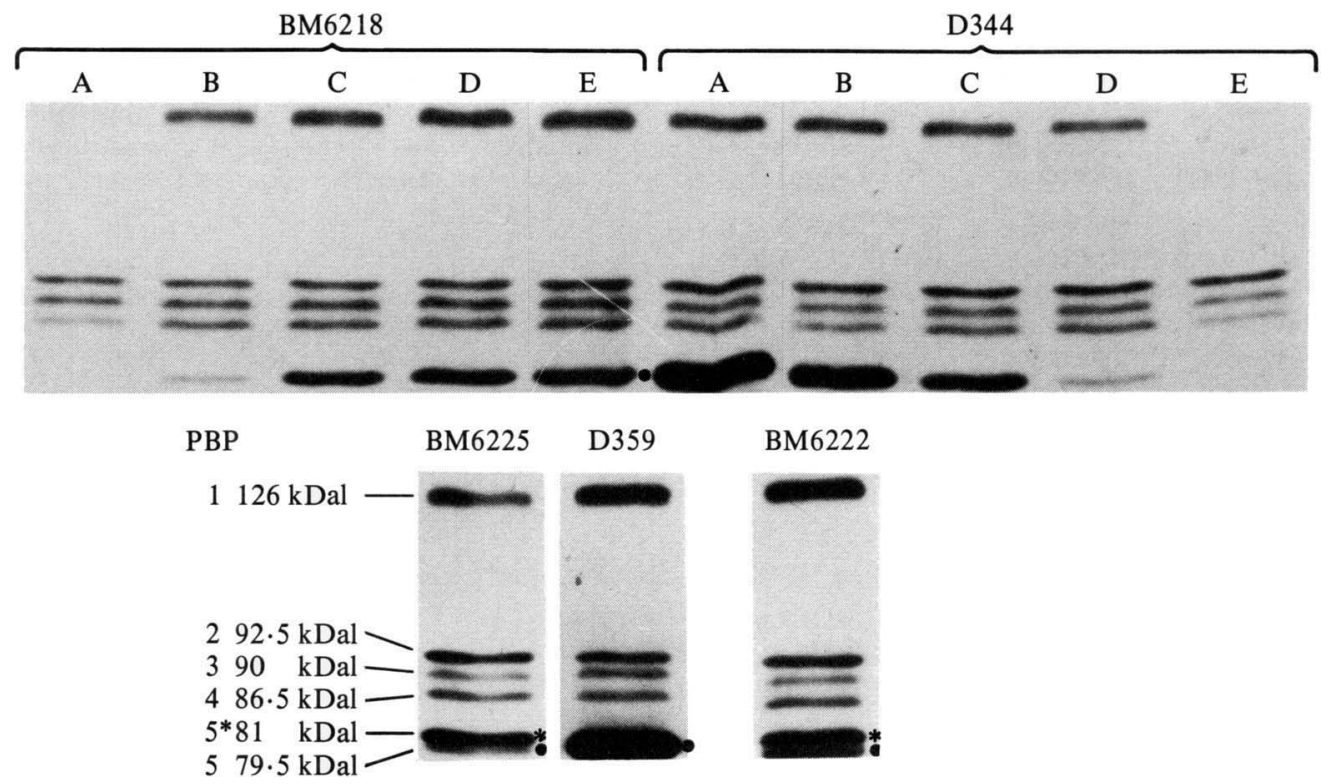

Fig. 1. Penicillin-binding proteins (PBPs) of parental and derivative strains of Enterococcus faecium. The PBPs of strains BM6218 and D344 are shown in tracks A-E after incubation of whole organisms with $20,2,0.2,0.02$ and $0.002 \mu \mathrm{g}\left[{ }^{3} \mathrm{H}\right]$ benzylpenicillin respectively. The PBPs of strains BM6225, D359 and BM6222 are shown after saturation with $20 \mu \mathrm{g}\left[{ }^{3} \mathrm{H}\right]$ benzylpenicillin. The PBPs of D371 were identical to those of D344 and D359. Estimated molecular weights are shown, and PBPs 5* (*) and 5 (O) are indicated. PBP6 is not shown, since it co-electrophoresed with the $\left[{ }^{3} \mathrm{H}\right]$ benzylpenicillin during SDS-PAGE.

$\begin{array}{llll}\text { PBP } & \text { D371 } & \text { BM6221 } & \text { BM6221/4 }\end{array}$

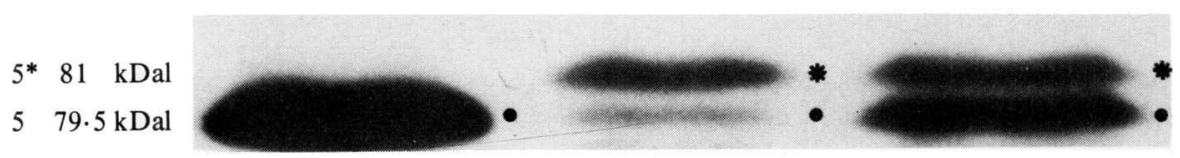

Fig. 2. Penicillin-binding proteins $5^{*}(*)$ and $5(\odot)$ detected under saturating conditions.

BM6222 and BM6221, obtained as spontaneous benzylpenicillin-susceptible derivatives from D371, had also lost resistance to all six antibiotics tested. Strains BM6225 and BM6218 were both obtained as spontaneous benzylpenicillin-susceptible derivatives from BM6224 and D344 respectively, but in the former case tetracycline resistance was also lost, whereas in the latter case there were no changes in resistance to the other four antibiotics. The spontaneous resistant mutants (BM6225/1, BM6225/2, BM6225/4, BM6221/0.5 and BM6221/4) selected with benzylpenicillin, at frequencies between $10^{-8}$ and $10^{-9}$, from strains BM6225 and BM6221 did not become resistant to other antibiotics.

The three resistant, clinical isolates D359 (Fig. 1), D371 and D344 (Fig. 1) had six PBPs, as did the erythromycin- or aminoglycoside-susceptible mutants (BM6223 and BM6224, and BM6219) isolated from D359 and D344, respectively. However, examination of the benzylpenicillin-susceptible mutants BM6225 (Fig. 1), BM6222 (Fig. 1) and BM6221 showed the presence of an extra band (PBP5*) and a significant reduction in the amount of PBP5, with a somewhat lower affinity in the two latter strains (Table 1). In contrast, there was no PBP5* in strain BM6218 (Fig. 1) derived from D344, and in this case the reduced quantity of PBP5 had a much higher affinity for benzylpenicillin than the parental strain. Examination of the PBPs in the resistant mutants selected in vitro (BM6225/1, BM6225/2, BM6225/4, BM6221/0.5 and BM6221/4; Fig. 2, Table 1) showed that the amounts of PBP5 were increased according to the 
Table 1. Antibiotic susceptibilities of parental and mutant strains of Enterococcus faecium, and characteristics of PBPs $5^{*}$ and 5

\begin{tabular}{|c|c|c|c|c|c|c|c|}
\hline \multirow[b]{2}{*}{ Strain } & \multirow[b]{2}{*}{$\begin{array}{l}\text { Selection } \\
\text { procedure* }\end{array}$} & \multirow[b]{2}{*}{$\begin{array}{l}\text { Resistance } \\
\text { profile† }\end{array}$} & \multirow[b]{2}{*}{$\begin{array}{c}\text { Pc MIC } \\
\left(\mu \mathrm{g} \mathrm{m}^{-1}\right)\end{array}$} & \multicolumn{2}{|c|}{ PBP5* $\ddagger$} & \multicolumn{2}{|c|}{ PBP5 $\ddagger$} \\
\hline & & & & Amount & $\mathrm{S}_{50}$ & Amount & $\mathrm{S}_{50}$ \\
\hline D359 & Wild-type & Pc Tc MLS Km Sm & 16 & - & & 10660 & $7 \cdot 0$ \\
\hline BM6223 & Spont & Pc Tc $\quad \mathrm{Km} \mathrm{Sm}$ & 16 & - & & 8580 & $6 \cdot 7$ \\
\hline BM6224 & $\mathrm{EtBr}$ & $\mathrm{Pc} T \mathrm{c}$ & 16 & - & & 9610 & $7 \cdot 7$ \\
\hline BM6225 & Spont & & 0.5 & 3980 & 1.6 & 620 & 14 \\
\hline BM6225/1 & Spont $\mathrm{Pc}$ & & 2 & 4080 & ND & 2320 & ND \\
\hline BM6225/2 & Spont $\mathrm{Pc}$ & & 4 & 3740 & ND & 5090 & ND \\
\hline BM6225/4 & Spont $\mathrm{Pc}$ & Pc & 8 & 3790 & ND & 8950 & ND \\
\hline D371 & Wild-type & Pc Tc MLS $\mathrm{Km} \mathrm{Sm} \mathrm{Cm}$ & 32 & - & & 11850 & 15 \\
\hline BM6222 & Spont & & 0.5 & 2990 & 1.7 & 530 & 41 \\
\hline BM6221 & Spont & & 0.125 & 2710 & $2 \cdot 3$ & 1060 & 50 \\
\hline BM6221/0.5 & Spont Pc & & 1 & 2950 & ND & 4140 & ND \\
\hline BM6221/4 & Spont $\mathrm{Pc}$ & Pc & 8 & 2320 & ND & 8390 & ND \\
\hline D344 & Wild-type & Pc Tc MLS Km Sm & 64 & - & & 8600 & 58 \\
\hline BM6219 & EtBr & Pc Tc MLS & 64 & - & & 9000 & 54 \\
\hline BM6218 & Spont & Tc MLS Km Sm & 0.031 & - & & 2050 & 1.6 \\
\hline
\end{tabular}

ND, Not done; - - not present.

* Spont, isolated as spontaneous susceptible or resistant mutant; $\mathrm{EtBr}$, isolated after treatment with ethidium bromide; Pc, benzylpenicillin.

$\dagger$ Pc, benzylpenicillin; Tc, tetracycline; MLS, macrolides (erythromycin), lincosamides, streptogramin B; Km, kanamycin; Sm, streptomycin; Cm, chloramphenicol.

$\ddagger$ Amounts (arbitrary units) were calculated from densitometry of fluorograms, and are the means of at least two experiments. PBPs were detected under saturating conditions with $\left[{ }^{3} \mathrm{H}\right]$ benzylpenicillin. $\mathrm{S}_{50}$ is the concentration $\left(\mu \mathrm{g} \mathrm{ml}^{-1}\right)$ of $\left[{ }^{3} \mathrm{H}\right]$ benzylpenicillin required to give $50 \%$ saturation.

Table 2. Antibiotic susceptibilities of clinical isolates of Enterococcus faecium, and characteristics of PBPs 5* and 5

Abbreviations are as in Table 1. Strains D359, D371 and D344 were the parental strains in Table 1.

\begin{tabular}{|c|c|c|c|c|c|c|c|}
\hline \multirow[b]{2}{*}{ Category } & \multirow[b]{2}{*}{ Strain } & \multirow[b]{2}{*}{$\begin{array}{l}\text { Resistance } \\
\text { profile }\end{array}$} & \multirow[b]{2}{*}{$\begin{array}{c}\text { Pc MIC } \\
\left(\mu \mathrm{g} \mathrm{ml}^{-1}\right)\end{array}$} & \multicolumn{2}{|c|}{ PBP5* } & \multicolumn{2}{|c|}{ PBP5 } \\
\hline & & & & Amount & $S_{50}$ & Amount & $\mathrm{S}_{50}$ \\
\hline 1 & $\begin{array}{l}\text { D383 } \\
\text { D378 } \\
\text { D65 }\end{array}$ & & $\begin{array}{l}0.062 \\
0.25 \\
0.5\end{array}$ & $\begin{array}{l}1930 \\
2030 \\
3990\end{array}$ & $\begin{array}{l}1 \cdot 1 \\
1 \cdot 8 \\
1 \cdot 4\end{array}$ & $\begin{array}{r}770 \\
1540 \\
1270\end{array}$ & $\begin{array}{l}23 \\
60 \\
37\end{array}$ \\
\hline 2 & $\begin{array}{l}\text { D61 } \\
\text { D66 } \\
\text { D63 } \\
9116 \\
9253 \\
9534 \\
9547\end{array}$ & Tc MLS & $\begin{array}{l}1 \\
1 \\
2 \\
4 \\
4 \\
4 \\
4\end{array}$ & $\begin{array}{l}3550 \\
3860 \\
3040 \\
3780 \\
3550 \\
4200 \\
4350\end{array}$ & $\begin{array}{l}2.7 \\
0.9 \\
1.5 \\
\text { ND } \\
\text { ND } \\
\text { ND } \\
\text { ND }\end{array}$ & $\begin{array}{l}4230 \\
4380 \\
4650 \\
3860 \\
3810 \\
4170 \\
4650\end{array}$ & $\begin{array}{l}75 \\
54 \\
46 \\
\text { ND } \\
\text { ND } \\
\text { ND } \\
\text { ND }\end{array}$ \\
\hline 3 & $\begin{array}{l}\text { D379 } \\
\text { D370 } \\
\text { D359 } \\
\text { D380 } \\
\text { D371 }\end{array}$ & $\begin{array}{l}\text { Pc Tc MLS Km Sm Cm } \\
\text { Pc Tc } \quad \mathrm{Sm} \\
\text { Pc Tc MLS Km Sm } \\
\text { Pc Tc MLS Km Sm } \\
\text { Pc Tc MLS Km Sm Cm }\end{array}$ & $\begin{array}{r}8 \\
8 \\
16 \\
16 \\
32\end{array}$ & $\begin{array}{l}- \\
- \\
- \\
-\end{array}$ & & $\begin{array}{r}9950 \\
13400 \\
10660 \\
9870 \\
11850\end{array}$ & $\begin{array}{r}12 \\
11 \\
7 \\
15 \\
15\end{array}$ \\
\hline 4 & $\begin{array}{l}\text { D368 } \\
\text { D360 }\end{array}$ & $\begin{array}{l}\text { Pc } \\
\text { Pc Tc MLS Km Sm }\end{array}$ & $\begin{array}{l}16 \\
16\end{array}$ & $\begin{array}{l}5530 \\
4880\end{array}$ & $\begin{array}{l}7 \cdot 1 \\
9.4\end{array}$ & $\begin{array}{l}8130 \\
8050\end{array}$ & $\begin{array}{l}12 \\
15\end{array}$ \\
\hline 5 & $\begin{array}{l}\text { D344 } \\
\text { D382 } \\
\text { D372 }\end{array}$ & $\begin{array}{l}\text { Pc Tc MLS Km Sm } \\
\text { Pc Tc MLS Km Sm Cm } \\
\text { Pc Tc MLS Km Sm Cm }\end{array}$ & $\begin{array}{r}64 \\
64 \\
128\end{array}$ & $\begin{array}{l}- \\
-\end{array}$ & & $\begin{array}{l}8600 \\
7790 \\
7950\end{array}$ & $\begin{array}{l}58 \\
\text { ND } \\
\text { ND }\end{array}$ \\
\hline 6 & D331 & Pc Tc MLS Km Sm & 128 & 2140 & 30 & 4510 & 77 \\
\hline
\end{tabular}


level of resistance, but that PBP5* remained at a level similar to that in the parental, susceptible strains BM6225 and BM6221 (Fig. 2).

The amounts of PBPs 1, 2, 3 and 4 differed by up to threefold between the various strains (data not shown), but there was no correlation with the resistance level. Moreover, the affinities of these PBPs for benzylpenicillin did not differ significantly in the strains. The mean (with standard deviation) concentrations of $\left[{ }^{3} \mathrm{H}\right]$ benzylpenicillin required to give $50 \%$ saturation $\left(\mathrm{S}_{50}\right.$ values) were ( $\left.\mu \mathrm{g} \mathrm{ml}^{-1}\right)$ : PBP1, 0.22 (0.04); PBP2, 0.020 (0.007); PBP3, 0.041 (0.021); and PBP4, $0 \cdot 11(0 \cdot 032)$. The respective values for PBP6, measured in the three clinical isolates and the susceptible derivatives under conditions allowing resolution of this PBP, were $0 \cdot 15(0 \cdot 049)$. Since all the PBPs had relatively high affinities for benzylpenicillin, and PBP5 in the wild-type strains had $S_{50}$ values in the range 0.5-1 $\times$ MIC, it seemed possible that PBP5 could be the essential PBP in these resistant organisms. In support of this, growth of the wild-type strains in nonradioactive benzylpenicillin at $0.2 \times$ MIC for each strain resulted in almost complete saturation of PBPs 1, 2, 3, 4 and 6, but only slight saturation of PBP5 with no inhibition of the growth rate, suggesting that the other PBPs are non-essential targets. Subsequent experiments were done to examine whether PBP5* as well as PBP5 existed in other wild-type strains.

\section{Antibiotic susceptibilities and PBPs in clinical isolates}

An additional 18 clinical isolates were chosen on the basis of a wide range of susceptibility to benzylpenicillin, the MIC values being from 0.062 to $128 \mu \mathrm{g} \mathrm{ml}^{-1}$, as shown in Table 2 which also includes the three wild-type, clinical isolates presented in Table 1. Most of the relatively benzylpenicillin-susceptible strains (MIC values $<8 \mu \mathrm{g} \mathrm{ml}^{-1}$ ) were susceptible to the other antibiotics tested. In contrast, 10 of the 11 benzylpenicillin-resistant strains (MIC values $>8 \mu \mathrm{g} \mathrm{ml}^{-1}$ ) were multiply resistant.

PBPs 1 to 4 and 6 were found in all of the additional 18 strains in amounts and with affinities similar to those given earlier for strains D359, D371 and D344, except that in two strains (D360 and D368) the molecular weight of PBP2 differed slightly from that in other strains, and strain D66 had no PBP4. These differences could not be correlated with the resistance levels to benzylpenicillin. PBP5* was found in 13 of the 21 isolates (Table 2), and this PBP was present mostly in the relatively benzylpenicillin-susceptible strains. The results concerning the amounts and affinities obtained with PBPs $5^{*}$ and 5 allowed the grouping of the organisms into six categories (Table 2), based primarily on the amounts of PBP5 and the presence or absence of PBP5*. Strains within each group had somewhat similar susceptibilities to benzylpenicillin, as well as similar amounts and $S_{50}$ values for PBPs $5^{*}$ and 5 . Two categories ( 3 and 5 ) did not contain PBP5*. When present, the amounts of PBP5* remained similar (with a twofold range) in the various strains, but the PBP had lower affinities for the antibiotic in the more resistant categories (4 and 6). In contrast, the amounts of PBP5 differed significantly (Student's $t$-test) between each of the six categories, and the mean values compared with that in category 1 were $3 \cdot 6,9 \cdot 4,6 \cdot 8,6 \cdot 8$ and $3 \cdot 8$ times greater in categories $2,3,4,5$ and 6 , respectively. The affinities of PBP5 for benzylpenicillin in categories 3 and 4 appeared higher than those of PBP5 in the other categories.

PBPs $5^{*}$ and 5 , or 5 alone if $5^{*}$ was not present, were the most abundant PBPs in each strain, accounting for an average of $49 \%$ of the total under saturating conditions. The lowest amounts were found in strain D378 where PBPs $5^{*}$ and 5 accounted for $37.5 \%$ of the total, and the greatest in strain D344 where PBP5 accounted for $68.9 \%$ of the total PBPs.

When whole cells or membranes obtained from the various clinical isolates of $E$. faecium were incubated for extended periods (up to $150 \mathrm{~min}$ ) under saturating conditions, there were no changes in the amounts of PBPs, and the results were identical to those obtained after $30 \mathrm{~min}$.

\section{DISCUSSION}

In the present studies, the loss of resistance to benzylpenicillin in two strains of Enterococcus faecium was associated with a significant decrease in the amounts of a low affinity PBP5, and a new PBP5* not present in the parental strains was detected in most of the spontaneous, 

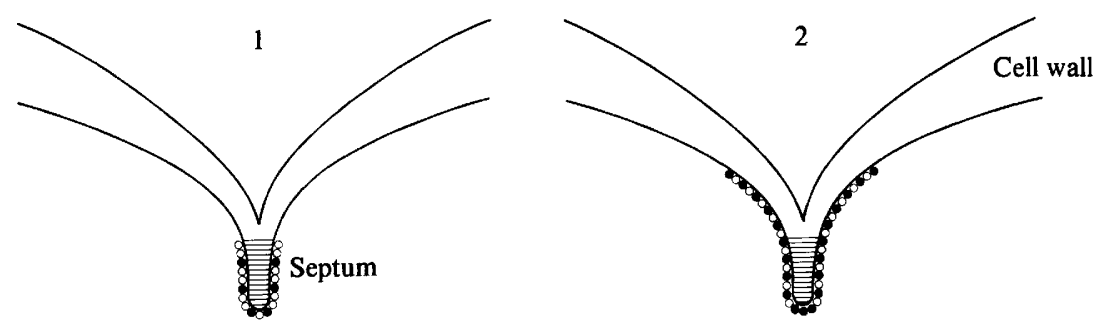

Fig. 3. Model of the primary growth and division site of Enterococcus faecium with localization of PBPs $5^{*}$ and 5. Diagrams 1 and 2 represent categories 1 and 2 of the clinical isolates described in Table 2, and show the relative amounts of PBP5* $(O)$ and PBP5 (O) adjacent to the septal wall. The total amounts of the PBPs are shown in proportion with that in category 1 , and the area in which synthesis of peptidoglycan occurs for ingrowth of the septum is shaded. It is assumed that PBPs $5^{*}$ and 5 outside this area are therefore not essential for this ingrowth. For the other categories of strains listed in Table 2, PBP5*, when present, and PBP5 would be included in the model in the amounts given.

susceptible derivatives. These results differ greatly from those of Eliopoulos et al. (1982), who found no changes in the PBPs of hypersusceptible derivatives of E. faecium, but this was probably due to insufficient saturation of PBP5 in the wild-type strains. Analysis of PBPs in the various clinical isolates in our study revealed that most organisms (64\%) contained both PBP5* and PBP5, and that six categories of strains could be defined on the basis of the amounts of PBP5, the presence or absence of PBP5*, and the affinity of PBP5* for benzylpenicillin. It would therefore seem likely that the natural susceptibility (or resistance) level of $E$. faecium to benzylpenicillin is related to the relative amounts as well as the relative affinities of two essential PBPs (5* and 5). Presumably, each of these proteins must have transpeptidase activity, and they must be the sole functional PBPs allowing continued growth of the organisms in concentrations of benzylpenicillin up to the minimal inhibitory concentration.

A possible mechanism is that PBPs $5^{*}$ and 5 could be primarily located at the primary growth and division site (septum) of the cocci, that only a limited number of enzyme molecules can be involved in peptidoglycan synthesis in a small area of the nascent wall, and that the relative abundance of one enzyme compared with the other could determine which would have the major role in synthesis (Fig. 3). For example, in category 1, PBP5* is present in double the amount of PBP5, which has the lower affinity. Therefore, when PBP5* becomes inhibited by benzylpenicillin, its function cannot be taken over by PBP5 since the acylated PBP5* would physically block access of PBP5 to the site of synthesis, or, alternatively, the low amount of PBP5 is not enough for continued peptidoglycan synthesis. Thus the high susceptibility of strains in this category is due to the inhibition of the higher affinity target even though the lower affinity PBP5 is present. Since the PBPs of E. faecium have extremely long half-lives when acylated with benzylpenicillin (Coyette et al., 1980; Williamson et al., 1983) it is unlikely that any great amounts of enzyme activity are regained by de-acylation of the complexes. Within category 2, the amount of PBP5 is increased about three- to fourfold, and more of this PBP could be present at the growth site. In this situation, a large proportion of PBP5* could be saturated but the lower affinity target would still have sufficient activity to allow continued growth at a greater concentration of the antibiotic than that occurring in category 1. Categories 3 and 5 contain strains having only PBP5, therefore the resistance level is dependent only on the amount and affinity of this PBP.

On the basis of this above model, it would be expected that overproduction of the lower affinity target (PBP5) would decrease the susceptibility of the organism, since the increased amount could displace some of, or take over from, the higher affinity target (PBP5*) at the site of synthesis. In the present studies, spontaneous resistant mutants were obtained with up to an eightfold increase in the quantity of PBP5, but with unchanged amounts of PBP5*. Although the PBPs involved in resistance of enterococci to benzylpenicillin have been described as "slowbinding PBPs' (Fontana et al., 1983), we would not define either PBP5* or PBP5 as such, since this apparent characteristic is due to the extremely low affinity for the antibiotic and very high concentrations of $\left[{ }^{3} \mathrm{H}\right]$ benzylpenicillin can give relatively rapid saturation of these PBPs. 
The occurrence of increased amounts of low affinity PBPs in resistant mutants, as described here for $E$. faecium and elsewhere for $E$. durans, E. faecalis and E. faecium (Daneo-Moore \& Pucci, 1982; Daneo-Moore et al., 1983; Fontana et al., 1983), as well as their partial loss in susceptible derivatives of $E$. faecium, must indicate that the amounts of these proteins are regulated, either genetically or physiologically. In contrast with the report of Daneo-Moore et al. (1983), we did not observe multiple changes in the amounts of cytoplasmic membrane proteins stained with Coomassie Blue, except for the partial loss of a $79.5 \mathrm{kDal}$ protein in the case of each of the susceptible derivatives (data not shown), and this protein had the same molecular weight as PBP5. The benzylpenicillin-susceptible mutants isolated by Eliopoulos et al. (1982) were also deficient in membrane proteins with molecular weights of $82 \mathrm{kDal}$ and $108 \mathrm{kDal}$, but neither of these corresponded to the molecular weights of the PBPs.

The basis for the appearance of PBP5* with partial loss of PBP5 in some susceptible derivatives obtained from strains lacking PBP5* is unknown at present. It is interesting that these derivatives would be placed in category 1 of Table 2 on the basis of the amounts of PBP5, whereas both parental strains are in category 3 . We speculate that $E$. faecium may be naturally relatively susceptible to benzylpenicillin, but that some mutation or other genetic change causes loss of PBP5* and overproduction of PBP5 resulting in resistance to the antibiotic. Thus the organisms in categories 3 and 5 may have been derived from those in categories 1 and 2 . Since the benzylpenicillin-resistant mutants selected in vitro only had increased amounts of PBP5, it seems possible that the loss of PBP5* and overproduction of PBP5 may have been separate events during the evolution of resistance. Nevertheless, the benzylpenicillin-susceptible derivatives containing PBP5* were obtained spontaneously from three wild-type, resistant strains at a relatively high frequency $\left(10^{-3}\right.$ to $\left.10^{-4}\right)$; therefore a single mutation or genetic change, different from that regulating only the amount of PBP5, may be responsible for the overall change. An alternative mechanism of resistance may be represented by the organisms in categories 4 and 6 , in which the decreased affinities of PBP5* could be more important than the increased amounts of PBP5. Previous reports have shown that losses of PBPs and changes in affinities as well as amounts of PBPs, probably due to several different mutations, contribute to the resistance of some strains of Streptococcus pneumoniae to benzylpenicillin (Handwerger \& Tomasz, 1984; Zighelboim \& Tomasz, 1980). We are currently investigating whether PBPs 5* and 5 have any biochemical homology. It seems unlikely that one is a degradation product of the other, since the continued incubation of whole cells or membranes with the radioactive benzylpenicillin did not change the amounts of either PBP.

Although the occurrence of benzylpenicillin-susceptible derivatives was generally associated with loss of resistance to a variety of other antibiotics, the derivative BM6218 obtained from D344 retained the other resistance markers. The apparent reason for the susceptibility in this case was a fourfold decrease in the amount of PBP5 together with a significant increase (about 35 -fold) in the affinity of this PBP for benzylpenicillin, and we have recently found virtually identical results with one of the pairs of resistant (4379) and hypersusceptible (4379-S) strains obtained from G. M. Eliopoulos and R. C. Moellering, Jr (data not shown). Therefore, the strains BM6218 and 4379-S may have had mutations in the structural genes coding for PBP5, revealing a basis for susceptibility in addition to the appearance of PBP5* and partial loss of PBP5.

This work was supported by grants from the Caisse Nationale de l'Assurance Maladie des Travailleurs Salariés to L. G. and R. W., and also to T. H.

\section{REFERENCES}

Coyette, J., Ghuysen, J.-M. \& Fontana, R. (1980). The penicillin-binding proteins in Streptococcus faecalis ATCC 9790. European Journal of Biochemistry 110, 445-456.

Daneo-Moore, L. \& Pucci, M. (1982). Penicillin tolerance and resistance in Streptococcus faecium. In Microbiology - 1982, pp. 199-203. Edited by D.
Schlessinger. Washington, DC: American Society for Microbiology.

Daneo-Moore, L., Pucci, M., Zito, E. \& Ferrero, M. (1983). Studies of $\beta$-lactam resistance in Streptococcus faecium. In Target of Penicillin, pp. 493-497. Edited by R. Hakenbeck, J.-V. Höltje \& H. Labischinski. Berlin: Walter de Gruyter. 
Eliopoulos, G. M., Wennersten, C. \& Moellering, R. C., JR (1982). Resistance to $\beta$-lactam antibiotics in Streptococcus faecium. Antimicrobial Agents and Chemotherapy 22, 295-301.

FACKLAM, R. R. (1972). Recognition of group D streptococcal species of human origin by biochemical and physiological tests. Applied Microbiology 23, 1131-1139.

Fontana, R., Cerini, R., Longoni, P., Grossato, A. \& CANEPARI, P. (1983). Identification of a streptococcal penicillin-binding protein that reacts very slowly with penicillin. Journal of Bacteriology 155, 1343-1350.

Handwerger, S. \& Tomasz, A. (1984). Both concentration and affinity of PBPs change in pneumococcal penicillin resistance. In Program and Abstracts. 24th Interscience Conference on Antimicrobial Agents and Chemotherapy, abstract 1000. Washington, DC: American Society for Microbiology.

Horodniceanu, T. \& Delbos, F. (1980). Group D streptococci in human infections: identification and sensitivity to antibiotics. Annales de Microbiologie 131B, 131-144.
Horodniceanu, T., Bouanchaud, D. H., Bieth, G. \& ChabBert, Y. A. (1976). R plasmids in Streptococcus agalactiae (group B). Antimicrobial Agents and Chemotherapy 10, 795-801.

Le Bouguénec, C. \& Horodniceanu, T. (1982). Conjugative R plasmids in Streptococcus faecium (group D). Antimicrobial Agents and Chemotherapy 21, 698-705.

Weinstein, A. J. \& Moellering, R. C., JR (1975). Studies of cephalothin: aminoglycoside synergism against enterococci. Antimicrobial Agents and Chemotherapy 7, 522-529.

Williamson, R., Calderwood, S. B., Moellering, R. C., JR \& Tomasz, A. (1983). Studies on the mechanism of intrinsic resistance to $\beta$-lactam antibiotics in group D streptococci. Journal of General Microbiology 129, 813-822.

Zighelboim, S. \& Tomasz, A. (1980). Penicillinbinding proteins of multiply antibiotic-resistant South African strains of Streptococcus pneumoniae. Antimicrobial Agents and Chemotherapy 17, 434-442. 